\title{
Central Bank Independence, Speed of Disinflation and the Sacrifice Ratio
}

\author{
Giuseppe Diana* and Moise Sidiropoulos ${ }^{\dagger}$
}

July 8, 2003

\begin{abstract}
This paper examines the impact of central bank independence on inflation persistence. Our theoretical analysis predicts that a higher degree of central bank independence leads to a lower inflation persistence and therefore to a higher speed of disinflation. The empirical results, provided using a 18 OECD countries sample, show that central bank independence is negatively related to the degree of inflation persistence. In addition, as there is a positive correlation between inflation persistence and the sacrifice ratio, we conclude that central bank independence, through its influence on inflation persistence, is negatively correlated to the sacrifice ratio.
\end{abstract}

Keywords: central bank independence, inflation persistence, speed of disinflation, sacrifice ratio

JEL Classification Numbers : E31, E52, E58

\section{Introduction}

The last decade witnessed a wave of changes towards central bank reforms in a number of countries, especially in the European Union. The main factor behind those central bank reforms was the belief that the independence of the central bank is an efficacious device for achieving low inflation and price stability. Indeed, many economists argue that Central Bank Independence (CBI), with a clear mandate to maintain price stability, may be an institutional mechanism through which the credibility of government commitments can be enhanced, raising thus the probability of the success of disinflationary policies through the change of the private sector inflationary expectations.

However, recent empirical studies investigating the relationship between CBI and disinflation costs (see, Debelle and Fischer, 1994; Walsh, 1994; Fischer, 1996; Gaertner, 1997; Jordan,1997; and Baltensperger and Kugler, 2000) report evidence that higher CBI implies higher disinflation costs. To rationalize these empirical findings, appearing somewhat surprising, a variety of explanations have been suggested. One of the most usual explanations (see for example Walsh, 1994) lies in the influence of CBI on the outputinflation tradeoff (i.e. the slope of the Phillips curve). As stated by the well established

*BETA-theme, Louis Pasteur University, Strasbourg (France) and GRICE-Tipee, Robert Schuman University, Strasbourg (France) corresponding author: diana@cournot.u-strasbg.fr

${ }^{\dagger}$ BETA-theme, Louis Pasteur University, Strasbourg (France) 
empirical result of Alesina and Summers (1993), CBI produces, on average, lower and less variable inflation. This, in turn, can lead to less frequent price and wage adjustments and, therefore, to a flatter short-run Phillips curve and higher disinflation costs (Lucas, 1973; Ball, Mankiw and Romer, 1988; and Jordan, 1997). Therefore, with a credible commitment to low inflation and price stability, indexation and short period contracts may become less prevalent, leading to more wage and price persistence.

Regardless of how convincing we consider such an explanation, it has to be pointed out that the speed of disinflation represents another important factor influencing the sacrifice ratio ${ }^{1}$. Actually, the optimal speed of disinflation (that is the choice between "gradualism" and "cold turkey") is a central issue for macroeconomic policy. According to Sargent (1983), disinflation is less costly if it is quick. He argues that a sharp regime-shift produces credibility, and hence expectations adjust sharply making disinflation costless. Ball (1994) finds, across his sample of disinflation episodes using cross-country data, that the speed of disinflation is inversely related to the size of the sacrifice ratios. In other words, he finds that a fast disinflation, a so-called "cold turkey" procedure, leads to smaller sacrifice ratios. Moreover, as noted by Cukierman (1992, p.273), inflation is usually a fairly persistent process. The speed at which the economy reacts to a change in its environment may be slow and the economy may not move quickly to a new equilibrium with lower price expectations. In this respect, the way economic agents perceive major changes in the policy regime (such as CBI) has important implications for the short-run impact of policy changes.

For these reasons, we focus in this paper on the influence of institutional rules, such as the CBI, on the degree of inflation persistence and therefore on the speed of disinflation and on the size of the disinflation costs. Recently, Jordan $(1997,1999)$ investigated the relationship between CBI and the speed of disinflation. He suggested that the speed of disinflation is connected to CBI and a lower degree of CBI leads to fast disinflation. According to Jordan (1999), both the non linear form of the Phillips curve and the size of the total disinflation cause this phenomenon. With a low degree of CBI, the shortrun Phillips curve is steeper and total disinflation is large. The disinflation process can be faster because the output loss is small. However, in his framework the degree of inflation persistence is exogenous and not affected by the degree of CBI. The purpose of this paper is to add to the literature by examining the way in which CBI affects the degree of inflation persistence and therefore the speed of disinflation. We first formulate a theoretical model which suggests that CBI and nominal wage indexation reduce the persistence of inflation and thereby increase the speed of disinflation (which is negatively related to the disinflation costs). We then provide some empirical evidence to test our theoretical results. These empirical findings support our theoretical results showing that CBI is associated with lower inflation persistence and higher speed of disinflation.

The rest of the paper is organized as follows. Section 2 sets up the theoretical framework. Section 3 discuss how the central bank independence is related to the speed of disinflation (through its influence on the inflation persistence) and thus to the disinflation costs. Section 4 presents our empirical results. Section 5 summarizes the main conclusions of the paper.

\footnotetext{
${ }^{1} \mathrm{~A}$ variety of additional factors such as the degree of nominal rigidities, the labor market characteristics, or the openness of an economy have been also taken into account (see, Ball, 1994).
} 


\section{The theoretical framework}

This section provides a simple theoretical game model to frame our analysis. Our objective is not to provide an exhaustive description of the role of the CBI, but rather to show that our results are consistent with the implication of highly stylized model in monetary policy. For our purpose, we consider a simple one-period Barro-Gordon [1983] model of monetary policy extended to allow for stochastic shocks and indexed wage contracts (see Gray [1976] and Fischer [1983]). Capital will be assumed fixed in the short-run, and output is given by the short-run production of the type:

$$
y_{t}=\alpha l_{t}+v_{t}
$$

where $y_{t}$ is the logarithm of output, $l_{t}$ is the logarithm of employment, $\alpha$ is the exponent of labor and is less than unity $(0<\alpha<1)$ and $v_{t}$ is a supply side shock (or productivity shock) which is assumed to follow the process:

$$
v_{t}=g_{y}+\phi v_{t-1}+\epsilon_{t}
$$

where $g_{y}$ is the deterministic growth rate of output (or productivity), the parameter $\phi$ $(0<\phi<1)$ determines the degree of autocorrelation in productivity shocks, and $\epsilon_{t}$ is a normally distributed shock with zero mean and a variance varying with $\phi$ so as to standardize the variance of $v_{t}$ at $\sigma_{v}^{2}$. That is $\epsilon_{t} \sim N\left[0,\left(1-\phi^{2}\right) \sigma_{v}^{2} I\right]$. Firms determine employment by equalizing the marginal product of labor to the real wage. This yealds the following employment demand function:

$$
l_{t}^{d}=\eta+[1 /(1-\alpha)]\left(p_{t}-w_{t}+v_{t}\right)
$$

where $\eta=\ln (\alpha) /(1-\alpha)>0, w_{t}$ is the logarithm of the nominal wage, $p_{t}$ is the log of price level in time $t$. The labor supply by workers is given by:

$$
l_{t}^{s}=\eta-\theta+\delta\left(p_{t}-w_{t}\right), \quad \delta \geqslant 0
$$

where the intercept term in (4) is not set equal to that of the demand for labor because we assume that the labor supply is affected by distortions factors in the labor market, captured by the parameter $\theta(\theta>0)^{2}$. Equating (3) and (4) under the assumption that $\delta=0$, without any loss of generality of our results, we obtain:

$$
\widehat{w}_{t}=p_{t}+v_{t}+(1-\alpha) \theta
$$

where $\widehat{w}_{t}$ is the competitive equilibrium nominal wage in the labor market that would arise in the absence of nominal wage contracts and leads to the following competitive equilibrium output level: $\widehat{y}_{t}=\bar{y}-k+v_{t}$, where $\bar{y}=\alpha \eta$, and $k=\alpha \theta$. Once wage contracts are signed at the beginning of each period, employment becomes demand determined.

\footnotetext{
${ }^{2}$ These distortions are assumed to be the result of either the income tax policies, or "insiders" behavior in the labor market which leads to an excessive base real wage.
} 
Thus, a moral hazard problem arise, justifying the incentive of workers to index their nominal wages to unexpected price movements (see, Gray, 1976) following the indexing rule:

$$
w_{t}=E_{t-1} \widehat{w}_{t}+\gamma\left(p_{t}-E_{t-1} p_{t}\right), \quad 1 \geqslant \gamma \geqslant 0
$$

where $E_{t-1}$ is the rational expectation operator and $\gamma$ is the indexing parameter. For $\gamma=1$, wages are fully indexed, for $\gamma=0$ are no indexed and for $0<\gamma<1$ are partially indexed. Finally, integrating the equation (6) into (3) and using (1), we obtain the following aggregate supply function:

$$
y_{t}=\bar{y}-k+\xi(1-\gamma)\left(\pi_{t}-E_{t-1} \pi_{t}\right)+(1+\xi) v_{t}
$$

where $\pi\left(\equiv p_{t}-p_{t-1}\right)$ is the inflation rate and $\xi=\alpha /(1-\alpha)$.

The government is assumed to minimize a loss function shared by the society and defined over inflation and output:

$$
L_{t}^{G}=\frac{1}{2}\left[\pi_{t}^{2}+\lambda\left(y_{t}-y_{t}^{*}\right)^{2}\right]
$$

In other words, the government dislikes deviations from both his inflation target, $\pi^{*}$ (assumed to be zero for simplicity) and his output target, $y_{t}^{*}$ (expressed in percentage points above natural output: $\left.y_{t}^{*}=\widehat{y}_{t}+k>0\right)$. The preference parameter $\lambda(\lambda>0)$ denotes the relative importance that government places on the output target and the inflation target. Since the government has no credible commitment technology available, it selects in the head of the central bank a "conservative" central banker by being more concerned about inflation that the government (see, Rogoff, 1985). This central banker minimizes the following loss function:

$$
L_{t}^{C B}=\frac{1}{2}\left[(1+\beta) \pi_{t}^{2}+\lambda\left(y_{t}-y_{t}^{*}\right)^{2}\right], \quad 0<\beta<\infty
$$

Equation (9) indicates that the central banker is the policymaker setting the inflation rate $\pi_{t}$ to achieve the targeted inflation and output outcomes. The government decides about the degree of the central banker conservatism denoted by the parameter $\beta$. Since $\beta$ is strictly greater than zero, the central banker places a greater relative weight on inflation stabilization than government does. In the following, we assume that no distinction is made between independence and conservatism ${ }^{3}$.

Consider a one-shot Nash equilibrium. The central banker sets his policy instrument $\pi_{t}$ in order to minimize the expected value of the loss function (9), taking $\pi_{t}^{e}$ and $v_{t-1}$ as given, and after observing the current-period supply shock. The private sector forms its rational expectations about inflation before observing the current-period shock $v_{t}$ and before the policymaker sets the inflation rate. The time-consistent rational expectations equilibrium is readily found as:

$$
\pi_{t}=\frac{\lambda \xi(1-\gamma)}{1+\beta}\left(k-\xi g_{y}\right)-\frac{\lambda \xi^{2}(1-\gamma)}{1+\beta+\lambda \xi^{2}(1-\gamma)^{2}} \epsilon_{t}-\frac{\lambda \xi^{2} \phi(1-\gamma)}{1+\beta} v_{t-1}
$$

\footnotetext{
${ }^{3}$ For an extensive discussion, see Eijffinger and De Haan (1996)
} 
Equation (10) reveals that the equilibrium inflation rate in each period is determined by three factors: $\lambda \xi(1-\gamma)\left(k-\xi g_{y}\right) /(1+\beta)$ is the permanent inflationary bias due to the discretionary policy, $\lambda \xi^{2}(1-\gamma) \epsilon_{t} /\left[1+\beta+\lambda \xi^{2}(1-\gamma)^{2}\right]$ is the inflation due to output stabilization in the present period, $\lambda \xi^{2} \phi(1-\gamma) v_{t-1} /(1+\beta)$ is the temporary inflationary bias due to past stabilization policy. The presence of the variable $v_{t-1}$ shows that equation (2) is an alternative and simpler way of introducing inflation persistence (see Bleaney [2001]).

\section{CBI and the speed of disinflation}

In this section, we focus on the effect of CBI on the speed of disinflation through its influence on the degree of inflation persistence. This persistence, measured by the correlation coefficient $\rho$ between $\pi_{t}$ and $\pi_{t-1}$ is given by:

$$
\rho=\frac{\operatorname{cov}\left(\pi_{t}, \pi_{t-1}\right)}{\operatorname{var}\left(\pi_{t}\right)}
$$

We now determine the variance of $\pi_{t}$ and the covariance of $\pi_{t}$ and $\pi_{t-1}$. The unconditional mean of the inflation rate, $\bar{\pi}$, amounts to:

$$
\bar{\pi}=\frac{\lambda \xi(1-\gamma)\left[k-\xi g_{y}\right]}{1+\beta}
$$

Equation (12)indicates that higher CBI (higher $\beta$ ) reduces the average inflation rate. Using equations (10) and (12), the unconditional variance of the inflation rate can be written as:

$$
\operatorname{var}\left(\pi_{t}\right)=\left[\frac{\lambda \xi^{2}(1-\gamma)}{1+\beta}\right]^{2}\left\{\phi^{2}+\left(\frac{1+\beta}{1+\beta+\lambda \xi^{2}(1-\gamma)^{2}}\right)^{2}\left(1-\phi^{2}\right)\right\} \sigma_{v}^{2}
$$

To obtain now the covariance of the inflation rates $\pi_{t}$ and $\pi_{t-1}$, we use equation (10) for the period $t-1$, and the fact that, from equation (2), $\phi v_{t-2}=g_{y}+v_{t-1}$. Consequently, we can write:

$$
\pi_{t-1}=\frac{\lambda \xi(1-\gamma)\left[k-\xi\left(g_{y}+v_{t-1}\right)\right]}{1+\beta}+\frac{\lambda \xi^{2}(1-\gamma)}{1+\beta} \epsilon_{t-1}-\frac{\lambda \xi^{2}(1-\gamma)}{1+\beta+\lambda \xi^{2}(1-\gamma)^{2}} \epsilon_{t-1}
$$

From equations (10) and (14), and assuming that $E\left(v_{t-1} \epsilon_{t-1}\right)=E\left(\epsilon_{t} \epsilon_{t-1}\right)=0$, we can define the covariance between $\pi_{t}$ and $\pi_{t-1}$ as ${ }^{4}$ :

$$
\operatorname{cov}\left(\pi_{t}, \pi_{t-1}\right)=E\left[\left(\pi_{t}-\bar{\pi}\right)\left(\pi_{t-1}-\bar{\pi}\right)\right]=\left[\frac{\lambda \xi^{2}(1-\gamma)}{1+\beta}\right]^{2} \phi \sigma_{v}^{2}
$$

\footnotetext{
${ }^{4}$ Note that the unconditional mean of $\pi_{t-1}$ is also equal to $\bar{\pi}$.
} 
Finally, using equations (11), (13) and (15), the correlation coefficient $\rho$ between the inflation rates $\pi_{t}$ and $\pi_{t-1}$ which measures the degree of inflation persistence, is obtained as:

$$
\rho=\phi\left[\frac{\left(1-\phi^{2}\right)(1+\beta)^{2}}{\left[1+\beta+\lambda \xi^{2}(1-\gamma)^{2}\right]^{2}}+\phi^{2}\right]^{-1}
$$

Taking the first derivative of (16) with respect to $\beta$ and $\gamma$, we get:

$$
\frac{\partial \rho}{\partial \beta}=-\frac{2 \phi \lambda \xi^{2}\left(1-\phi^{2}\right)(1+\beta)(1-\gamma)^{2}}{\left[1+\beta+\lambda \xi^{2}(1-\gamma)^{2}\right]^{3}}\left\{\frac{\left(1-\phi^{2}\right)(1+\beta)^{2}}{\left[1+\beta+\lambda \xi^{2}(1-\gamma)^{2}\right]^{2}}+\phi^{2}\right\}^{-2}<0
$$

and

$$
\frac{\partial \rho}{\partial \gamma}=-\frac{4 \phi \lambda \xi^{2}\left(1-\phi^{2}\right)(1+\beta)^{2}(1-\gamma)}{\left[1+\beta+\lambda \xi^{2}(1-\gamma)^{2}\right]^{3}}\left\{\frac{\left(1-\phi^{2}\right)(1+\beta)^{2}}{\left[1+\beta+\lambda \xi^{2}(1-\gamma)^{2}\right]^{2}}+\phi^{2}\right\}^{-2}<0
$$

Equation (17) provides the major new result of this paper. It states that where the degree of CBI is greater, the degree of inflation persistence is lower, ceteris paribus. Moreover, equation (18) indicates that nominal wage indexation also negatively affects the degree of inflation persistence.

Finally, the speed of disinflation can be related to the degree of inflation persistence, $\rho$. Theoretically, the disinflation process lasts an infinitely long time. However, for a meaningful determination of the speed of disinflation, the infinite process has to be cut off. Consequently, we compute the absolute speed of disinflation, $s$, as the size of the disinflation between $t-1$ and $t$ (see, Jordan 1999):

$$
s=\pi_{t-1}-\pi_{t}
$$

Starting from a situation with an initial inflation $\pi_{t-1}$ equal to its mean $\bar{\pi}$, and assuming that the inflation rate follows an $A R(1)$ process: $\pi_{t}=\rho \pi_{t-1}$, where $\rho$ is the correlation coefficient (or degree of inflation persistence), we can write:

$$
s=(1-\rho) \bar{\pi}=\left\{1-\phi\left[\frac{\left(1-\phi^{2}\right)(1+\beta)^{2}}{\left[1+\beta+\lambda \xi^{2}(1-\gamma)^{2}\right]^{2}}+\phi^{2}\right]^{-1}\right\} \bar{\pi}
$$

where it is assumed that the average inflation rate $\bar{\pi}$ is considered as given when policymaker determines the inflation rate in a specific period ${ }^{5}$. From equation (20), we show

\footnotetext{
${ }^{5}$ Considering in this analysis a policymaker with a short-run (a single period) horizon optimizing on a period-by-period basis, we assume that the average inflation rate is independent of the choice of the inflation rate and, therefore, the policymaker takes average inflation rate as given when determines the inflation rate in a specific period. With an infinite horizon, the planned sequence of inflation would affect the average inflation rate, so that the policymaker has to take the impact on average inflation into account. However, the extension to an infinite horizon is not crucial for the relevance of the results of this single period model delivering basically the same qualitative results as the infinite horizon model (see, Jordan, 1999).
} 
that the the speed of disinflation, $s$, is related to the degree of inflation persistence, $\rho$, and consequently to the degree of central bank independence $\beta$ and the degree of nominal wage indexation $\gamma$.

Taking the first derivative of (20) with respect to $\rho$, we easily get $\partial s / \partial \rho<0$. Then, using the previous results (i.e.: $\partial \rho / \partial \beta<0$ and $\partial \rho / \partial \gamma<0$ ), we obtain:

$$
\begin{aligned}
& \frac{\partial s}{\partial \beta}=\frac{\partial s}{\partial \rho} \cdot \frac{\partial \rho}{\partial \beta}>0 \\
& \frac{\partial s}{\partial \gamma}=\frac{\partial s}{\partial \rho} \cdot \frac{\partial \rho}{\partial \gamma}>0
\end{aligned}
$$

Equation (21) states that a higher degree of CBI results in a higher speed of disinflation. This, in turn, should result in a smaller cost of disinflation (i.e. a smaller sacrifice ratio). Equation (22) indicates that a higher degree of nominal wage indexation leads to faster, and hence less costly, disinflation.

As suggested by our analysis the speed of disinflation is connected to the degree of CBI. A higher degree of CBI leads to fast disinflation. Consequently, this theoretical result does not suggest, as it was, quite surprisingly, the case in previous analysis (see, Jordan, 1999), that a lower degree of CBI leads to fast disinflation. In fact, it suggests exactly the opposite and looks consistent with the main conclusions of the CBI literature. Actually, as originally suggested by Sargent (1983), the speed of disinflation is an indicator of credibility because a speedier disinflation is a visible sign of seriousness of the commitment to disinflating. And as CBI is an institutional mechanism through which the credibility of policymakers can be enhanced, CBI should increase the speed of disinflation. On the other hand, nominal wage indexation is a factor that determine the inflation-output trade-off (or the slope of the short-run Phillips) but also the speed of disinflation. In other words, wage setters adjust more frequently their wage contracts and the economy move more quickly to a new equilibrium with low inflation by increasing the speed of disinflation and creating a potential gain in terms of output and unemployment. Consonant with the Sargent (1983) view, and the Ball (1994) empirical findings, a fast disinflation (that is, a high speed of disinflation or a so-called "cold turkey" procedure) leads to smaller sacrifice ratios.

\section{Empirical evidence}

In this section, the theoretical insights suggested by the previous analysis are empirically investigated. The main testable implication of the theory is that the inflation persistence (or the speed of disinflation) is negatively (positively) affected by the degree of CBI and the degree of nominal wage indexation. Another testable hypothesis is that the disinflations costs are negatively related to the inflation persistence. In order to test the robustness of these predictions, we need quantitative measures of the costs of disinflation, the inflation persistence, the degree of CBI and nominal wage indexation. In this respect, 
our empirical analysis is based on a sample of 56 observations of disinflation episodes for 18 OECD countries from $1960-90^{6}$.

Dependent Variable: Inflation Persistence (INPA)

\begin{tabular}{|c|c|c|c|c|c|c|}
\hline & $(1)$ & $(2)$ & $(3)$ & (4) & $(5)$ & (6) \\
\hline constant & $\begin{array}{c}1.129^{* * *} \\
(5.610)\end{array}$ & $\begin{array}{c}0.677^{* * *} \\
(5.989)\end{array}$ & $\begin{array}{c}1.602^{* * *} \\
(6.482)\end{array}$ & $\begin{array}{c}0.728^{* * *} \\
(4.658)\end{array}$ & $\begin{array}{c}1.249^{* * *} \\
(4.197)\end{array}$ & $\begin{array}{c}0.672^{\text {*** }} \\
(3.770)\end{array}$ \\
\hline LVAU & $\begin{array}{c}-0.773^{* *} \\
(2.488)\end{array}$ & $\begin{array}{c}-0.666^{* *} \\
(2.156)\end{array}$ & & & & \\
\hline AS & & & $\begin{array}{c}-0.243^{* * *} \\
(3.897)\end{array}$ & $\begin{array}{l}-0.111 \\
(1.677)\end{array}$ & & \\
\hline GMT & & & & & $\begin{array}{c}-0.045^{*} \\
(1.987)\end{array}$ & $\begin{array}{l}-0.026 \\
(1.154)\end{array}$ \\
\hline NWRE & $\begin{array}{c}-0.077^{* *} \\
(2.568)\end{array}$ & & $\begin{array}{c}-0.115^{* * *} \\
(3.954)\end{array}$ & & $\begin{array}{c}-0.084^{* *} \\
(2.323)\end{array}$ & \\
\hline NWRI & & $\begin{array}{c}0.236^{*} \\
(1.941)\end{array}$ & & $\begin{array}{c}0.196 \\
(1.420)\end{array}$ & & $\begin{array}{c}0.194 \\
(1.220)\end{array}$ \\
\hline Nobs & 16 & 18 & 14 & 16 & 14 & 15 \\
\hline SEE & 0.181 & 0.186 & 0.149 & 0.200 & 0.197 & 0.218 \\
\hline$R^{2}$ & 0.409 & 0.283 & 0.632 & 0.214 & 0.355 & 0.142 \\
\hline
\end{tabular}

Table 1: CBI, NWI and Average Inflation Persistence (INPA) over the 1960-1990 period

Notes : t-statistics in parentheses. $*, * *$ and $* * *=$ significant at the 10,5 and $1 \%$ level

Concerning the costs of disinflation, the most commonly used measure is the sacrifice ratio which may be defined as the number of percentage points of lost output associated with a policy-induced $1 \%$ reduction in inflation. There are three common methods for calculating this measure. The first method, suggested by Ball (1994), involves the identification of actual periods of disinflation for individual countries and then the calculation of changes in the output gap relative to changes in inflation over those periods. The second method, offered by Hutchinson and Walsh (1998), consists of calculating sacrifice ratios for individual countries based on time-series estimates of short-run Phillips curves. The third method, provided by Cecchetti and Rich (2001), construct sacrifice ratio estimates using three different structural VAR models. However, economists remain sceptical about the ability of current econometric techniques to provide an accurate measurement of disinflation costs. In the following, we use the Ball's estimates of sacrifice ratio issued by the first method. The simplicity of this method has the disadvantage that it does not control for additional factors which may influence the output gap. However, this allows us to performe regressions using sacrifice ratio estimates for quite short time periods for a relatively large number of countries. Table 6 in appendix gives estimates of sacrifice

\footnotetext{
${ }^{6}$ The countries are Australia, Austria, Belgium, Canada, Denmark, Finland, France, Germany, Ireland, Italy, Japan, New Zealand, the Netherlands, Spain, Sweden, Switzerland, the United Kingdom, and the United States. These are the same 18 countries examined, and for which CBI measures are generated, in Grilli et al. (1991), Alesina and Summers (1993) and in Cukierman (1992).
} 
Dependent Variable: Inflation Persistence (INPD)

\begin{tabular}{rcccccc}
\hline \hline & $(1)$ & $(2)$ & $(3)$ & $(4)$ & $(5)$ & $(6)$ \\
\hline \multirow{2}{*}{ constant } & $0.799^{* * *}$ & $0.486^{* * *}$ & $0.937^{* * *}$ & $0.478^{* * *}$ & $0.707^{* * *}$ & $0.440^{* * *}$ \\
& $(7.018)$ & $(7.796)$ & $(5.523)$ & $(5.886)$ & $(4.324)$ & $(5.212)$ \\
& & & & & & \\
LVAU & $-0.342^{*}$ & $-0.271^{*}$ & & & & \\
& $(1.948)$ & $(1.703)$ & & & & \\
AS & & & $-0.093^{* *}$ & -0.026 & & \\
& & & $(2.211)$ & $(0.790)$ & & \\
GMT & & & & & -0.010 & -0.002 \\
& & & & & $(0.795)$ & $(0.212)$ \\
NWRE & $-0.047^{* * *}$ & & $-0.057^{* * *}$ & & $-0.037^{*}$ & \\
& $(2.788)$ & & $(2.845)$ & & $(1.859)$ & \\
NWRI & & $0.203^{* * *}$ & & $0.138^{*}$ & & 0.128 \\
& & $(3.065)$ & & $(1.831)$ & & $(1.593)$ \\
Nobs & 50 & 56 & 43 & 49 & 43 & 46 \\
SEE & 0.181 & 0.179 & 0.179 & 0.188 & 0.187 & 0.189 \\
$R^{2}$ & 0.150 & 0.157 & 0.171 & 0.069 & 0.084 & 0.061 \\
\hline \hline
\end{tabular}

Table 2: CBI, NWI and Inflation Persistence over Disinflationary episodes (INPD)

Notes : t-statistics in parentheses. $*, * *$ and $* * *=$ significant at the 10,5 and $1 \%$ level

ratio (SRB) for the 18 OECD countries of our sample over the 56 disinflationary episodes identified by Ball (1994).

The procedure adopted here to obtain inflation persistence estimates, consists of calculating inflation persistence for individual countries based on time-series estimates of the $A R(1)$ process: $\pi_{t}=a+b \pi_{t-1}+u_{t}$, where the parameter $b$ is an estimate of inflation persistence. The regressions are based on quarterly observations of consumer prices (CPI) for the 18 OECD countries of our sample over the period 1960-1990 (see, OECD, Main Economic Indicators). Three alternative indices of the inflation persistence are provided. The first index is the INflation Persistence over Desinflation episodes denoted by INPD, and is obtained by performing regressions over the 56 disinflationary episodes identified by Ball (1994). The second index is the INflation Persistence on Average, denoted by INPA. It reflects the average degree of inflation persistence over the whole period and is obtained by performing regressions for each country over the period 1960-90. The third index, denoted by INPM (INflation Persistence Mean), is obtained as the mean of the degree of inflation persistence constructed using the estimates for each country over the 56 disinflation episodes. The second column of Table 6 shows the results of INPD estimates, the third column gives estimates for INPA.

Finally, to test the influence of central bank independence (CBI) and the nominal wage indexation (NWI) on the inflation persistence, three alternative indices of CBI and two indices of NWI are used. The first index of CBI, denoted by LVAU, is the index for legal independence developed by Cukierman [1992]. The second index, denoted by GMT, is the total index of political and economic independence suggested by Grilli, Masciandaro and 
Dependent Variable: Inflation Persistence (INPA)

\begin{tabular}{|c|c|c|c|c|c|c|}
\hline & (1) & $(2)$ & $(3)$ & (4) & $(5)$ & $(6)$ \\
\hline constant & $\begin{array}{l}1.122^{* * *} \\
(10.686)\end{array}$ & $\begin{array}{l}0.649^{* * *} \\
(10.708)\end{array}$ & $\begin{array}{l}1.604^{* * *} \\
(12.592)\end{array}$ & $\begin{array}{c}0.694^{* * *} \\
(8.609)\end{array}$ & $\begin{array}{c}1.274^{* * *} \\
(8.239)\end{array}$ & $\begin{array}{c}0.671^{* * *} \\
(7.795)\end{array}$ \\
\hline LVAU & $\begin{array}{c}-0.791^{* * *} \\
(4.883)\end{array}$ & $\begin{array}{c}-0.589^{* * *} \\
(3.815)\end{array}$ & & & & \\
\hline AS & & & $\begin{array}{c}-0.246^{* * *} \\
(7.766)\end{array}$ & $\begin{array}{c}-0.097^{* * *} \\
(2.993)\end{array}$ & & \\
\hline GMT & & & & & $\begin{array}{c}-0.048^{* * *} \\
(4.163)\end{array}$ & $\begin{array}{c}-0.027^{* *} \\
(2.393)\end{array}$ \\
\hline NWRE & $\begin{array}{c}-0.074^{* * *} \\
(4.788)\end{array}$ & & $\begin{array}{c}-0.115^{\text {*** }} \\
(7.637)\end{array}$ & & $\begin{array}{c}-0.085^{* * *} \\
(4.517)\end{array}$ & \\
\hline NWRI & & $\begin{array}{l}0.222^{* * *} \\
(3.449)\end{array}$ & & $\begin{array}{l}0.183^{* *} \\
(2.447)\end{array}$ & & $\begin{array}{l}0.203^{* *} \\
(2.417)\end{array}$ \\
\hline Nobs & 50 & 56 & 43 & 49 & 43 & 46 \\
\hline SEE & 0.167 & 0.174 & 0.134 & 0.187 & 0.178 & 0.198 \\
\hline$R^{2}$ & 0.405 & 0.272 & 0.639 & 0.201 & 0.369 & 0.158 \\
\hline
\end{tabular}

Table 3: CBI, NWI and Average Inflation Persistence (INPA) over disinflationary episodes

Notes : t-statistics in parentheses. $*, * *$ and $* * *=$ significant at the 10,5 and $1 \%$ level

Tabellini [1991]. The third index is the index, denoted by AS, is provided by Alesina and Summers [1993]. The nominal wage indexation (NWI) is approximated by two alternative proxies. The first index, denoted by NWRE, is the Bruno and Sachs's [1985] index of "nominal wage responsiveness". Higher values mean greater flexibility, that is, shorter, more indexed and more synchronized wage agreements. The second index, denoted by NWRI, is the Grubb et alii (1983) index of "nominal wage rigidity" which is increasing with nominal wage rigidity.

We start by testing the first testable implication of our analysis. Tables 1, 2, 3 and 4 report regression results where the dependent variable is the inflation persistence. The three alternative indices of central bank independence (LVAU, AS and GMT) and the two alternative indices of nominal wage indexation (NWRE and NWRI) are regressed, respectively, on the three index of inflation persistence (INPA, INPD and INPM). The expected signs on the coefficients are that greater CBI decreases the inflation persistence, the greater nominal wage responsiveness (NWRE) reduces inflation persistence, and the greater nominal wage rigidity (NWRI) increases the inflation persistence. The key result reported in these tables is consistent across all regressions and shows that the degree of CBI has always a negative coefficient. This negative coefficient is statistically significant for most of the regressions performed. Moreover, the degre of NWRE (NWRI) has always a negative (positive) coefficient. These coefficients also look statistically significant in most of the regressions. Therefore, these findings support our two theoretical results according to which CBI and NWI are negatively related to inflation persistence. In particular, these estimates provide a strong indication that countries whose central banks are more 
Dependent Variable: Inflation Persistence (INPM)

\begin{tabular}{|c|c|c|c|c|c|c|}
\hline & (1) & (2) & (3) & (4) & (5) & (6) \\
\hline constant & $\begin{array}{l}0.798^{* * *} \\
(10.376)\end{array}$ & $\begin{array}{l}0.486^{* * *} \\
(12.379)\end{array}$ & $\begin{array}{c}0.936^{* * * *} \\
(9.024)\end{array}$ & $\begin{array}{c}0.478^{* * *} \\
(9.423)\end{array}$ & $\begin{array}{c}0.706^{* * *} \\
(6.561)\end{array}$ & $\begin{array}{c}0.440^{* * *} \\
(7.999)\end{array}$ \\
\hline LVAU & $\begin{array}{c}-0.341^{* * *} \\
(2.872)\end{array}$ & $\begin{array}{c}-0.270^{* * *} \\
(2.697)\end{array}$ & & & & \\
\hline AS & & & $\begin{array}{c}-0.093^{* * *} \\
(3.609)\end{array}$ & $\begin{array}{l}-0.026 \\
(1.264)\end{array}$ & & \\
\hline GMT & & & & & $\begin{array}{l}-0.010 \\
(1.200)\end{array}$ & $\begin{array}{l}-0.002 \\
(0.322)\end{array}$ \\
\hline NWRE & $\begin{array}{c}-0.047^{* * *} \\
(4.117)\end{array}$ & & $\begin{array}{c}-0.057^{* * *} \\
(4.643)\end{array}$ & & $\begin{array}{c}-0.037^{* * *} \\
(2.815)\end{array}$ & \\
\hline NWRI & & $\begin{array}{c}0.203^{* * *} \\
(4.872)\end{array}$ & & $\begin{array}{c}0.138^{* * *} \\
(2.934)\end{array}$ & & $\begin{array}{l}0.128^{* *} \\
(2.447)\end{array}$ \\
\hline Nobs & 50 & 56 & 43 & 49 & 43 & 46 \\
\hline SEE & 0.122 & 0.113 & 0.109 & 0.117 & 0.124 & 0.123 \\
\hline$R^{2}$ & 0.278 & 0.320 & 0.355 & 0.160 & 0.174 & 0.134 \\
\hline
\end{tabular}

Table 4: CBI, NWI and Mean Inflation Persistence (INPM) over disinflationary episodes

Notes : t-statistics in parentheses. $*, * *$ and $* * *=$ significant at the 10,5 and $1 \%$ level

Dependent Variable: Sacrifice Ratio

\begin{tabular}{rcccccc}
\hline \hline & $(1)$ & $(2)$ & $(3)$ & $(4)$ & $(5)$ & $(6)$ \\
\hline \multirow{2}{*}{ constant } & -0.559 & 0.303 & -0.308 & $-0.856^{* *}$ & -0.464 & $-1.212^{* *}$ \\
& $(1.668)$ & $(0.746)$ & $(0.596)$ & $(2.390)$ & $(0.999)$ & $(2.182)$ \\
& & & & & & \\
INPD & $2.873^{* * *}$ & & & $2.553^{* * *}$ & & \\
& $(4.497)$ & & & $(3.976)$ & & \\
INPA & & 1.002 & & & $1.119^{*}$ & \\
& & $(1.423)$ & & & $(1.690)$ & \\
INPM & & & $2.360^{* *}$ & & & $2.678^{* * *}$ \\
& & & $(2.315)$ & & & $(2.825)$ \\
LENGTH & & & & $0.133^{* *}$ & $0.206^{* * *}$ & $0.219^{* * *}$ \\
& & & & $(2.003)$ & $(2.883)$ & $(3.190)$ \\
Nobs & 56 & 56 & 56 & & & \\
SEE & 0.906 & 1.043 & 1.013 & 0.882 & 0.979 & 0.937 \\
$R^{2}$ & 0.272 & 0.036 & 0.090 & 0.324 & 0.167 & 0.237 \\
\hline \hline
\end{tabular}

Table 5: Sacrifice Ratio and Inflation persistence

Notes : t-statistics in parentheses. $*, * *$ and $* * *=$ significant at the 10,5 and $1 \%$ level 
independent tend to find their inflation less persistent and disinflation faster trough an increase of the speed of disinflation.

The second testable hypothesis of our analysis is the positive (negative) relationship between the inflation persistence (speed of disinflation) and the size of the sacrifice ratios. The results of the performed regressions are reported in Table 5. In particular, the three alternative indices of inflation persistence (INPD, INPA and INPM) and the length of the disinflation episodes (LENGHT) issued by Ball's statistics are regressed on the the sacrifice ratio (SRB) which is the dependent variable. The key result is consistent across all regressions. A lower inflation persistence (a higher disinflation speed) decreases the costs of disinflation. This result confirms the findings in Ball (1994), where for a given amount of disinflation, a "cold_turkey" procedure is more efficient than a gradual disinflation procedure. In addition, to further analyze our conclusion that CBI affects the sacrifice ratio through the disinflation speed, we look at the impact of the CBI on the inflation persistence and thus on the speed of disinflation. The results reported in Tables 1, 2 and 3 show that the signs of the coefficients for all indices of CBI are negative. Therefore, there is an evidence that more independent central banks disinflate faster and with a lower output cost of disinflation. This impact of central bank independence on the sacrifice ratio therefore comes entirely from a negative (positive) correlation between the CBI and the inflation persistence (speed of disinflation). Finally, our results reveals that the choice of the disinflation procedure, between "gradualism" and "cold-turkey", is not independent of the degree of central bank independence. These results contrast to some extent with the empirical findings of some previous studies, where more independent central banks disinflate more slowly and CBI is positively correlated to the sacrifice ratios.

\section{Conclusion}

In this paper, we examine how CBI is associated with the output costs of disinflation through its influence on the inflation persistence and thus on the speed of disinflation. Theoretically, a monetary game model is developed and predicts that a higher degree of CBI leads to a a higher speed of disinflation through its influence on the degree of inflation persistence.

The empirical results, based on a sample of 56 observations of disinflation episodes for 18 OECD countries, lead to the following main conclusions: CBI is negatively related to the degree of inflation persistence. There is a positive correlation between the degree of inflation persistence and the size of the sacrifice ratios. Therefore, through the influence on the speed of disinflation, CBI is negatively related to the size of sacrifice ratios. Considering CBI as a possible determinant of cross-country differences in the costs of disinflation, our results represent a new contribution to the literature, given the previous, somewhat surprising, report a positive relationship between sacrifice ratios and CBI.

\section{References}

[1] Alesina A. and L. Summers (1993), Central Bank Independence and Macroeconomic Performance: Some Comparative Evidence, Journal of Money, Credit, and Banking, 25, 2, pp. 151-162. 
[2] Bade R. and M. Parkin (1988), Central Bank Laws and Monetary Policy, Working Paper Department of Economics University of Western Ontario.

[3] Ball L. (1994), What Determine the Sacrifice Ratio?, in N.G. Mankiw (ed.), Monetary Policy, University of Chicago Press, Chicago, IL.

[4] Ball L., G. Mankiw and D. Romer (1988), The New Keynesian Economics and the Output-Inflation Trade-Off, Brooking Papers on Economic Activity, 1:1-65.

[5] Baltensperger E. and P. Kugler (2000), Central Bank Independence and Sacrifice Ratios: Some Further Considerations, Open economies review, 11, pp.111-125.

[6] Barro R. and D. Gordon (1983), Rules, Discretion and Reputation in a Model of Monetary Policy, Journal of Monetary Economics, 12, pp. 101-121.

[7] Bleaney M. (2001), Exchange Rate Regimes and Inflation Persistence, IMF Staff Papers, Vol. 47, No. 3

[8] Bruno M. and J. Sachs (1985), The Economics of Worlwide Stagflation, Harvard University Press, Cambridge, MA.

[9] Cecchetti S. and R. Rich (2001), Structural estimates of the US sacrifice ratio, Journal of Business and Economics Statistics, 19: No. 4, 416-427.

[10] Cukierman A. (1992), Central Bank Strategy, Credibility, and Independence. MIT Press, Cambridge Mass.

[11] Debelle, G. and S. Fischer [1994], How Independent Should a Central Bank Be? In J. Fuhrer (ed.) Goals, Guidelines, and Constraints Facing Monetary Policymaker, Federal Reserve Bank of Boston.

[12] Eijffinger S. and J. De Haan (1996), The Political Economy of Central Bank Independence, Princeton Special Papers in International Economics.

[13] Fischer A. (1996), Central Bank Independence and Sacrifice Ratios, Open economies review, 7, pp.5-18.

[14] Fischer S. (1983), On Indexing and Inflation, Journal of Monetary Economics, 12, pp. 519-541.

[15] Gaertner, M. (1997), Central Bank Independence and Sacrifice Ratio : The Dark Side of the Force. Swiss Journal of Economics and Statistics 133(3): 512-538.

[16] Gray J.-A. (1976), Wage indexation: A Macroeconomic Analysis, Journal of Monetary Economics, 2, pp. 221-235.

[17] Grilli V., D. Masciandaro and G. Tabellini (1991), Public Financial Policies in Industrialized Countries, Economic Policy, 13, pp. 341-392.

[18] Grubb D., R. Jackman, and R.Layard (1983), Wage Rigidity and Unemployment in OECD Countries, European Economic Review, 21 (1/2): 11-39. 
[19] Hutchinson M. and C. Walsh (1988), The output inflation trade-off and central bank reform: evidence from New Zeland, Economic Journal, 703-725.

[20] Jordan T. (1997), Disinflation Costs, Accelerating Inflation Gains, and Central bank independence, Weltwirtschaftliches Archiv, 133, 1, pp. 1-21.

[21] Jordan T. (1999), Central Bank Independence and Sacrifice Ratio, European Journal of Political Economy, Vol. 15 (1999) 229-255.

[22] Lucas R. (1973), Some International Evidence on Output-Inflation Trade-Offs, American Economic Review 63: 326-334.

[23] Rogoff K. (1985), The Optimal Degree of Commitment to an Intermediate Monetary Target, Quarterly Journal of Economics, 100, pp. 1169-1189.

[24] Sargent T. (1983), Stoping Moderate Inflation: The Methods of Poincare and Thatcher, In R.Dornbusch and M. Simonsen (eds), Inflation, Debt, and Indexation, Cambridge, Mass.: MIT Press

[25] Walsh C.(1994), Central Bank Independence and the Short-Run Output-Inflation Trade-Off in EC, Working Paper 1.35, Center for German and European Studies, University of California at Berkeley. 


\begin{tabular}{|c|c|c|c|c|c|c|c|}
\hline Episode & $\mathrm{SRB}$ & INPD & INPA & Episode & SRB & INPD & INPA \\
\hline Australia & & & & Italy & & & \\
\hline 1974-78 & 0.4665 & 0.410 & 0.596 & $1963-67$ & 2.2857 & 0.407 & 0.794 \\
\hline \multirow[t]{2}{*}{$1982-84$} & 0.7571 & 0.312 & 0.596 & $1976-78$ & 0.5107 & 0.315 & 0.794 \\
\hline & & & & $1980-87$ & 1.6448 & 0.777 & 0.794 \\
\hline \multicolumn{8}{|l|}{ Austria } \\
\hline $1964-66$ & -0.5019 & 0.218 & 0.229 & Japan & & & \\
\hline $1974-78$ & 1.0824 & 0.396 & 0.229 & $1962-66$ & -0.6262 & 0.295 & 0.393 \\
\hline \multirow[t]{2}{*}{$1980-86$} & 1.3120 & 0.144 & 0.229 & $1974-78$ & 0.4615 & 0.465 & 0.393 \\
\hline & & & & $1980-86$ & -0.3842 & 0.225 & 0.393 \\
\hline \multicolumn{8}{|l|}{ Belgium } \\
\hline $1965-67$ & 0.7376 & 0.376 & 0.700 & Netherlands & & & \\
\hline $1974-78$ & 0.4945 & 0.753 & 0.700 & $1965-67$ & 1.2767 & 0.220 & 0.241 \\
\hline \multirow[t]{2}{*}{$1982-87$} & 1.7156 & 0.809 & 0.700 & $1975-78$ & -0.8558 & 0.361 & 0.241 \\
\hline & & & & $1980-86$ & 0.8234 & 0.609 & 0.241 \\
\hline \multicolumn{8}{|l|}{ Canada } \\
\hline $1969-70$ & 0.9863 & 0.615 & 0.758 & New-Zealand & & & \\
\hline $1974-76$ & 0.3822 & 0.523 & 0.758 & $1971-72$ & 0.5396 & 0.587 & 0.664 \\
\hline \multirow[t]{2}{*}{$1981-85$} & 2.2261 & 0.856 & 0.758 & $1975-78$ & 1.2897 & 0.653 & 0.664 \\
\hline & & & & $1980-83$ & 0.1752 & 0.455 & 0.664 \\
\hline Denmark & & & & $1982-88$ & 0.1018 & 0.387 & 0.664 \\
\hline 1968-69 & -0.6939 & 0.232 & 0.194 & & & & \\
\hline $1974-76$ & 0.5746 & 0.345 & 0.194 & Spain & & & \\
\hline \multirow[t]{2}{*}{$1980-85$} & 1.7621 & 0.571 & 0.194 & $1962-63$ & -0.5630 & 0.316 & 0.544 \\
\hline & & & & 1964-69 & -0.2142 & 0.370 & 0.544 \\
\hline Finland & & & & $1977-87$ & 3.4847 & 0.254 & 0.544 \\
\hline $1964-65$ & -0.3582 & 0.633 & 0.664 & & & & \\
\hline $1967-69$ & 0.9459 & 0.723 & 0.664 & Sweden & & & \\
\hline $1974-78$ & 1.6569 & 0.758 & 0.664 & $1965-68$ & 1.1134 & 0.254 & 0.311 \\
\hline \multirow[t]{2}{*}{$1980-86$} & 0.6477 & 0.669 & 0.664 & 1976-78 & 0.3564 & 0.472 & 0.311 \\
\hline & & & & $1980-86$ & 0.3357 & 0.322 & 0.311 \\
\hline \multicolumn{8}{|l|}{ France } \\
\hline $1962-66$ & -0.6765 & 0.343 & 0.823 & Switzerland & & & \\
\hline $1974-77$ & 1.0807 & 0.539 & 0.823 & $1966-68$ & 1.6060 & 0.544 & 0.483 \\
\hline \multirow[t]{2}{*}{$1981-86$} & 0.2517 & 0.868 & 0.823 & $1974-76$ & 1.3447 & 0.547 & 0.483 \\
\hline & & & & $1981-83$ & 1.2618 & 0.362 & 0.483 \\
\hline Germany & & & & $1984-86$ & -0.7917 & 0.361 & 0.483 \\
\hline $1965-67$ & 1.5614 & 0.386 & 0.399 & & & & \\
\hline $1974-77$ & 3.1974 & 0.437 & 0.399 & $U . K$. & & & \\
\hline \multirow[t]{2}{*}{$1980-86$} & 2.0739 & 0.622 & 0.399 & $1961-63$ & 1.7717 & 0.652 & 0.577 \\
\hline & & & & $1975-78$ & -0.0682 & 0.380 & 0.577 \\
\hline Ireland & & & & $1980-86$ & 1.0202 & 0.379 & 0.577 \\
\hline $1964-66$ & 0.9134 & 0.462 & 0.508 & & & & \\
\hline $1974-78$ & 0.8147 & 0.193 & 0.508 & U.S.A. & & & \\
\hline \multirow[t]{3}{*}{$1981-87$} & 0.4292 & 0.597 & 0.508 & 1969-71 & 3.3666 & 0.807 & 0.812 \\
\hline & & & & $1974-76$ & 1.6057 & 0.638 & 0.812 \\
\hline & & & & 1979-85 & 1.9362 & 0.782 & 0.812 \\
\hline
\end{tabular}

Table 6: Disinflation Episodes for Various Countries and Inflation Persistence 